\title{
СТАТЬИ
}

УДК $630 * 181: 582$

ФОРМОВОЕ РАЗНООБРАЗИЕ ГЕОГРАФИЧЕСКИХ КУЛЬТУР ЕЛИ НА ЕВРОПЕЙСКОМ СЕВЕРЕ РОССИИ (АРХАНГЕЛЬСКАЯ ОБЛАСТЬ)

Ежов А.В., Юдина О.А.

ФГАОУ ВО «Северный (Арктический) федеральный университет имени М.В. Ломоносова», Архангельск,e-mail:ezhov.av@edu.narfu.ru

Для современной территории Европейского Севера очень характерно наличие весьма нестабильных климатических условий, а также достаточно медленное восстановление леса. Как следствие, на данной территории стали наблюдать редкое и слабое естественное воспроизводство семян, что породило необходимость в активном использовании завозных семян. На этом фоне существенно повысилась значимость изучения географической изменчивости в связи с использованием данных географических культур, а особенную актуальность это приобретает не только для теории лесного хозяйства, но и для практики указанной деятельности. На этом фоне в качестве цели настоящей статьи выступает анализ закономерностей популяционной, видовой и географической изменчивости ели обыкновенной, а также ее видов и географических рас в связи с выращиванием в географических культурах. Исследования проведены в географических культурах ели, а в качестве ответственного субъекта за создание культур выступил Архангельский институт леса и лесохимии (Северный НИИ лесного хозяйства). Руководителем работ выступила Т.С. Непогодьева. Географические культуры ели были заложены в 1977 году на территории Плесецкого лесхоза Архангельской области на площади 8 га. В целях исследования культуры ели того или иного географического происхождения в районах, где были проведены испытания, представлены в 14 физико-географических районах. Гладкокорая ель занимает доминирующее положение (65-88\%). Пластинчатый тип коры характеризован высокими показателями средней высоты деревьев. В зависимости от типа ветвления выявлены три формы ели, в частности: щетковидное ветвление, гребенчатое, неправильно гребенчатое ветвление. Результаты, полученные в результате проведенного исследования, позволили детализировать факторы влияния генетики на ключевые параметры ели (показатели роста, тип коры и иные) и видовую принадлежность климатипов.

Ключевые слова: формовое разнообразие, географические культуры, популяция, климатип, ель

\section{A FORM VARIETY CONIFEROUS IN THE EUROPEAN NORTH OF RUSIA (ARKHANGELSK REGION)}

Ezhov A.V., Yudina O.A.

FSAEI HE «Northern (Arctic) Federal University named after M.V. Lomonosov», Arkhangelsk, e-mail:ezhov.av@edu.narfu.ru

\begin{abstract}
The modern territory of the European North is characterized by very unstable climatic conditions, as well as a rather slow restoration of the forest. As a result, a rare and weak natural reproduction of seeds began to be observed in this area, which gave rise to the need for the active use of imported seeds. Against this background, the importance of studying geographic variability has significantly increased in connection with the use of data from geographic crops, and this is of particular relevance not only for the theory of forestry, but also for the practice of this activity. Against this background, the purpose of this article is to analyze the patterns of population, species and geographic variability of the common spruce, as well as its species and geographic races in connection with growing in geographic crops. The studies were carried out in geographic spruce crops, and the Arkhangelsk Institute of Forestry and Wood Chemistry (Northern Research Institute of Forestry) acted as the responsible entity for the creation of crops. The work supervisor was T.S. Nepogodiev. Spruce geographical crops were established in 1977 on the territory of the Plesetsk forestry enterprise of the Arkhangelsk region on an area of 8 hectares. For the purposes of research, spruce cultures of one or another geographical origin in the areas where the tests were carried out are presented in 14 physiographic regions. Smooth-bark spruce occupies a dominant position (65-88\%). The lamellar type of bark is characterized by high values of the average height of trees. Depending on the type of branching, three forms of spruce were identified, in particular, brush-like branching, comb-shaped, irregular-comb branching. The results obtained as a result of the study made it possible to detail the factors of influence of genetics on the key parameters of spruce (growth indicators, bark type, and others) and species affiliation of climatypes.
\end{abstract}

Keywords: form variety, provenance trial, population, climatype, spruce

На Европейском Севере нестабильные климатические условия, медленные процессы лесовосстановления, слабое и редкое производство семян привели к ситуации, в рамках которой объективной необходимостью выступило использование привозного семенного материала. На этом фоне анализ географической изменчивости, проведенный с использованием ряда географических культур, приобретает особое значение для теории, равно как и для практики лесного хозяйства и изучения данной отрасли.

Известно, что первоначальное формирование и последующее испытание различных климатических экотипов (популяций) в рамках географических культур выступает в качестве достаточно универсального средства, применяемого в целях изучения 
того, каким образом древесные растения реагируют на изменения климата. Сравнение развития потомств деревьев различного географического происхождения одного возраста в однородных условиях произрастания направлено на оценку особенностей их адаптации и на выделение среди них наиболее устойчивых видов для создания высокопродуктивных и здоровых посадок [1].

В связи с этим повышение продуктивности елей, а также повышение их устойчивости в рамках Европейского Севера, отличающегося достаточно суровым климатом, по праву можно назвать ключевой задачей лесного хозяйства. Одновременно с этим данная задача едва ли может быть решена без рациональной и обоснованной с научной точки зрения организации системы лесного семеноводства. Вместе с тем в настоящее время есть только опыт хаотичного перемещения семян в рамках восстановления леса, а назвать результаты деятельности подобного рода положительными едва ли представляется возможным. В качестве ключевого метода подбора происхождений для работ по восстановлению леса выступают географические культуры [2].

Для достижения цели исследования необходимо было выполнить следующие задачи: составить таксационную характеристику 14 северных климатических типов ели; изучить состояние и рост климатических типов ели; дать сравнительную оценку изученных культур по морфологическим признакам (кора, тип ветвления).

Цель исследования заключается в определении основных закономерностей географической, популяционной и видовой изменчивости ели обыкновенной, которая относится к различным видам и расам при выращивании в различных географических культурах.

C географическим происхождением культур тесно связана приживаемость, сохранность, устойчивость к болезням. Климатипы по-разному реагируют на засуху, на устойчивость к морозу. Наследственность потомства проявляется в фенологических, морфологических, физико-биохимических показателях. С географическим происхождением тесно сплетена и репродуктивная способность культур [3].

Стоит отметить, что географические культуры образуют собой достаточно уникальные объекты, которые представляют определенный интерес как для лесного хозяйства в целом, так и для научных исследований, проводимых в данной области. В связи с этим создание и последующее ис- пытание климатических популяций в рамках географических культур выступает в качестве универсального средства для изучения того, каким образом древесные растения реагируют на изменение климата. Сравнение потомства одного возраста, но различного происхождения, которое испытывается в одинаковых условиях произрастания, направлено на выявление и оценку их адаптационных способностей и на выделение среди всех экземпляров более устойчивых. Именно более устойчивые виды впоследствии применяются для создания высокопродуктивных и здоровых насаждений, что представляется вполне естественным [4].

Одновременно с этим, в отличие от естественно выросших насаждений, выживаемость ели в потомствах определенного географического происхождения будет осуществляться в рамках различной способности климатипов к адаптации, что во многом обусловлено нарушением привычных для них условий роста [5]. Кроме того, изменение условий их среды достаточно часто порождает резкое формообразование, что во многом обусловлено реализацией мобилизационных резервов на фоне сохранения гетерогенности популяции [6].

\section{Материалы и методы исследования}

Исследования проведены в географических культурах ели, а в качестве ответственного субъекта за создание данных культур выступил Архангельский институт НИИ под руководством Т.С. Непогодьевой. Географические культуры ели были заложены в 1977 году суммарной площадью 8 га на территории Плесецкого лесхоза. В качестве первоначального насаждения, которое впоследствии было использовано для сбора семян, выступили ельники зеленомошной группы леса. Стоит отметить, что все географические культуры были созданы на основе единой методики: 3-летние саженцы вручную, с помощью лопат, высаживали рядами, а расстояние между ними было равно 2,5 м. В каждом ряду данное расстояние составило $0,75 \mathrm{M}$, длина блока была равна 50 м, а число посаженных деревьев зависело от того, был ли в наличии необходимый посадочный материал.

В целях проведения исследования в 2021 году было отобрано порядка 14 физико-географических районов, климатипы отражены в таблице 1 . Отметим, что регистрационные номера климатипов присвоены согласно реестру по формированию единой государственной сети в сфере географиче- 
ских культур [7]. Наименование по лесорастительным подрайонам и районам было дано в соответствии с классификацией С.Ф. Курнаева и в соответствии с паспортами географических культур [8]. Указанными вариантами были охвачены ареалы произрастания ели европейской (Picea abies (L.) Karst.) и ели сибирской (Picea obovata L.) в зоне их интрогрессивой гибридизации на территории европейской части РФ: в частности, от северной подзоны тайги до южной подзоны смешанных лесов и северной подзоны лиственных лесов соответственно.

В рамках обследования культур были проведены измерения диаметра ствола на высоте груди не менее 100 штук деревьев для каждого климатипа. Стоит отметить, что высота была отмечена для всех 100 деревьев, у которых был измерен диаметр. Приживаемость географических культур учитывалась путем перечета деревьев на учетных рядах. При перечетах деревья делились на 3 категории: здоровые, ослабленные и усохшие.

Bce популяции ели были изучены с учетом широкой совокупности признаков, к числу которых можно отнести такие, как интенсивность роста, тип ветвления и тип коры. Кроме того, в зависимости от того, какова интенсивность роста, учетные деревья поделены на классы Крафта. На базе данной классификации все ели были поделены на три основных класса:

1) 1 - лидеры (господствующие деревья);

2) 2 - согосподствующие деревья;

3) 4, 5 - отмирающие и угнетенные.

Также деревья были дифференцированы на шкалы по форме коры. В частности, на гладкокорые, пластинчатокорые, продольно-трещиноватые, чешуйчатокорые деревья.

Тип ветвления побегов устанавливался по Сильвену, деревья разделили на следующие группы: 1) с гребенчатым типом ветвления; 2) с неправильно гребенчатым типом ветвления; 3) с более щетковидным типом ветвления; 4) с плосковетвистым типом ветвления. Для изучения разнообразия форм ели тип ветвления был определен для 100 деревьев в каждой области выборки по срединным точкам кроны, которые были наиболее характерными в соответствии с установленными признаками [9].

\section{Результаты исследования и их обсуждение}

Исследования, которые были проведены в 43-летних географических культурах ели, показали, что на практике имеет место достаточно существенное влияние особенностей климатипов на выживание в объективно новых условиях объективной действительности, что отражено в таблице 1. Установлено, что с длиной вегетационного периода связь разделения приживаемости 43-летних культур умеренная и носит обратный характер.

Отпад особей за предшествующие 18 лет для всех климатипов составляет 10,5\%. Во многом это обусловлено естественным самоизреживанием климатипов. В свою очередь, деревья, которые относятся к угнетенным или умирающим, погибают [10]. Это позволяет сделать вывод о том, что приживаемость контрольного климатипа снизилась на 4\% и составила 74\%. Наиболее низкий показатель отпада характерен для климатипов Свердловской области (40-41 климатип) 0,4 и 0,2\% соответственно, как наиболее адаптированных к природно-климатическим условиям места испытания.

Полагаем, что в качестве ключевой причины снижения климатических типов ели в южных популяциях выступает низкая устойчивость к ранневесенним и позднеосенним заморозкам и зимним температурам. Впоследствии это порождает потерю роста и иные неблагоприятные последствия.

В географических культурах, имеющих южное происхождение из районов весьма широкого распространения европейских елей и близких к ним гибридов, наблюдается снижение числа особей по сравнению с северными популяциями ели сибирской, что можно проследить в таблице 2.

Наибольший процент отпада за последние 18 лет наблюдается у ели сибиррской в северотаежной зоне $-6,3 \%$, и у ели гибрридной с прризнаками еврропейской в южнотаежной зоне - 6,2\%. Наименьший отпад у ели сибиррской в среднетаежной и южнотаежной зонах - 0,4 и 0,2\% соответственно.

В данном случае сохраняется закономерность по снижению приживаемости с севера на юг, что уже было отмечено ранее и обусловлено различной продолжительностью периода вегетации в пункте испытания и на родине произрастания.

При оценке встречаемости видов ели по типу коры отмечено, что пластинчатый вид коры встречается единично, гладкокорая ель занимает доминирующее положение (65-88\%). Согласно данным, приведенным в таблице 3, пластинчатый тип коры характеризован высокими показателями средней высоты деревьев, хотя присутствует единично на местах произрастания. 
Таблица 1

Характеристика климатипов ели

\begin{tabular}{|c|c|c|c|c|c|c|c|c|}
\hline \multirow[b]{2}{*}{ 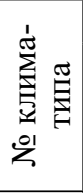 } & \multicolumn{2}{|c|}{ Происхождение семян } & \multicolumn{5}{|c|}{ Приживаемость, \% } & \multirow[b]{2}{*}{$\begin{array}{c}\text { Отпад за } \\
\text { последние } \\
18 \text { лет, \% }\end{array}$} \\
\hline & $\begin{array}{l}\text { Область, край, } \\
\text { республика, } \\
\text { лесхоз }\end{array}$ & \begin{tabular}{|c|} 
Лесорастительная \\
подзона по \\
С.Ф. Курнаеву \\
(1973) \\
\end{tabular} & $\begin{array}{c}\text { на } \\
3 \text { год }\end{array}$ & $\begin{array}{c}\text { на } \\
7 \text { год }\end{array}$ & $\begin{array}{c}\text { на } \\
11 \text { год }\end{array}$ & $\begin{array}{c}\text { на } \\
25 \text { год }\end{array}$ & $\begin{array}{c}\text { на } \\
43 \text { год }\end{array}$ & \\
\hline 1 & $\begin{array}{l}\text { Мурманская } \\
\text { Мончегорский }\end{array}$ & $\begin{array}{l}\text { Северная подзона } \\
\text { тайги }\end{array}$ & 75,2 & 75,2 & 70,0 & 70,0 & 66,5 & 3,5 \\
\hline 20 & $\begin{array}{l}\text { Архангельская } \\
\text { Пинежский }\end{array}$ & $\begin{array}{l}\text { Северная подзона } \\
\text { тайги }\end{array}$ & 88,3 & 88,3 & 83,9 & 81,3 & 76,3 & 5 \\
\hline 23 & $\begin{array}{l}\text { Архангельская } \\
\text { Холмогорский }\end{array}$ & $\begin{array}{l}\text { Северная подзона } \\
\text { тайги }\end{array}$ & 89,5 & 87,5 & 82,1 & 74,7 & 64,2 & 10,5 \\
\hline 40 & \begin{tabular}{|l|} 
Свердловская \\
Карпинский \\
\end{tabular} & $\begin{array}{l}\text { Средняя подзона } \\
\text { тайги }\end{array}$ & 86,2 & 79,2 & 67,0 & 54,5 & 54,1 & 0,4 \\
\hline 41 & $\begin{array}{l}\text { Свердловская } \\
\text { Н.-Тагильский }\end{array}$ & $\begin{array}{l}\text { Южная подзона } \\
\text { тайги }\end{array}$ & 92,6 & 91,5 & 70,5 & 60,5 & 60,3 & 0,2 \\
\hline 2 & $\begin{array}{l}\text { Карелия } \\
\text { Сегежский }\end{array}$ & $\begin{array}{l}\text { Средняя подзона } \\
\text { тайги }\end{array}$ & 85,3 & 84,4 & 77,2 & 68,7 & 67,7 & 1,0 \\
\hline 19 & $\begin{array}{l}\text { Архангельская } \\
\text { Плесецкий }\end{array}$ & $\begin{array}{l}\text { Средняя подзона } \\
\text { тайги }\end{array}$ & 89,3 & 89,3 & 83,5 & 78,4 & 74,4 & 4,0 \\
\hline 35 & \begin{tabular}{|l|} 
Удмуртия \\
Ижевский \\
\end{tabular} & $\begin{array}{l}\text { Северная подзона } \\
\text { смешанных лесов }\end{array}$ & 84,9 & 84,9 & 76,1 & 62,2 & 58,9 & 3,3 \\
\hline 7 & $\begin{array}{l}\text { Псковская } \\
\text { Великолукский }\end{array}$ & $\begin{array}{l}\text { Северная подзона } \\
\text { смешанных лесов }\end{array}$ & 88,8 & 88,0 & 72,6 & 49,8 & 48,1 & 1,7 \\
\hline 8 & $\begin{array}{l}\text { Эстония } \\
\text { Вильядинский }\end{array}$ & $\begin{array}{l}\text { Южная подзона } \\
\text { смешанных лесов }\end{array}$ & 88,6 & 87,6 & 71,4 & 50,0 & 42,7 & 7,3 \\
\hline 4 & $\begin{array}{l}\text { Карелия } \\
\text { Пудожский }\end{array}$ & $\begin{array}{l}\text { Средняя подзона } \\
\text { тайги }\end{array}$ & 90,9 & 88,4 & 82,4 & 65,4 & 64,1 & 1,3 \\
\hline 24 & $\begin{array}{l}\text { Вологодская } \\
\text { Череповецкий }\end{array}$ & $\begin{array}{l}\text { Южная подзона } \\
\text { тайги }\end{array}$ & 91,5 & 88,1 & 68,5 & 52,5 & 46,8 & 5,7 \\
\hline 27 & $\begin{array}{l}\text { Костромская } \\
\text { Галичский }\end{array}$ & $\begin{array}{l}\text { Южная подзона } \\
\text { тайги }\end{array}$ & 91,2 & 89,6 & 86,3 & 68,7 & 62,1 & 6,6 \\
\hline $29 a$ & $\begin{array}{l}\text { Московская } \\
\text { Загорский } \\
\end{array}$ & $\begin{array}{l}\text { Южная подзона } \\
\text { смешанных лесов }\end{array}$ & 92,6 & 91,6 & 81,4 & 66,6 & 65,7 & 0,9 \\
\hline
\end{tabular}

Таблица 2

Анализ приживаемости культур ели различного географического происхождения в зависимости от лесорастительных подзон

\begin{tabular}{|c|c|c|c|c|c|c|}
\hline \multirow{2}{*}{$\begin{array}{c}\text { Лесорастительная } \\
\text { подзона по С.Ф. Курнаеву (1973) }\end{array}$} & \multicolumn{5}{|c|}{ Приживаемость, \%, в возрасте, лет } & \multirow{2}{*}{$\begin{array}{c}\text { Отпад } \\
\text { за последние } \\
18 \text { лет, \% } \\
\end{array}$} \\
\hline & 3 & 7 & 11 & 25 & 43 & \\
\hline \multicolumn{7}{|c|}{ Ель сибирская } \\
\hline Северотаежная & 84,3 & 83,7 & 78,7 & 75,3 & 69 & 6,3 \\
\hline Среднетаежная & 86,2 & 79,2 & 67,0 & 54,5 & 54,1 & 0,4 \\
\hline Южнотаежная & 92,6 & 91,5 & 70,5 & 60,5 & 60,3 & 0,2 \\
\hline \multicolumn{7}{|c|}{ Ель европейская } \\
\hline Северная подзона смешанных лесов & 88,8 & 88,0 & 72,6 & 49,8 & 48,1 & 1,7 \\
\hline Южная подзона смешанных лесов & 90,6 & 89,6 & 76,4 & 58,3 & 54,2 & 4,1 \\
\hline \multicolumn{7}{|c|}{ Ель гибридная с признаками сибирской } \\
\hline Среднетаежная & 87,3 & 86,9 & 80,4 & 73,6 & 71,1 & 2,5 \\
\hline \multicolumn{7}{|c|}{ Ель гибридная с признаками европейской } \\
\hline Среднетаежная & 90,9 & 88,4 & 82,4 & 65,4 & 64,1 & 1,3 \\
\hline Северная подзона смешанных лесов & 84,9 & 84,9 & 76,1 & 62,2 & 58,9 & 3,3 \\
\hline Южнотаежная & 91,4 & 88,9 & 77,4 & 60,6 & 54,5 & 6,2 \\
\hline
\end{tabular}


Таблица 3

Показатели роста климатипов ели по типу коры $\left(\mathrm{t}_{0,05}=1,96\right)$

\begin{tabular}{|l|c|c|c|}
\hline \multirow{2}{*}{ Вид } & \multicolumn{3}{|c|}{ Высота, м } \\
\cline { 2 - 4 } & Пластинчатая & Чешуйчатая & Гладкокорая \\
\hline Ель сибирская & - & $\frac{9,2}{2,4-15,0}$ & $\frac{10,6}{1,7-15,0}$ \\
\hline Ель европейская & $\frac{13,0}{11,0-15,0}$ & $\frac{13,7}{6,0-15,0}$ & $\frac{11,1}{1,6-15,0}$ \\
\hline Ель гибридная с признаками сибирской & - & $\frac{11,2}{1,0-14,5}$ & $\frac{10,5}{1,6-14,0}$ \\
\hline Ель гибридная с признаками европейской & $\frac{13,8}{13,0-14,0}$ & $\frac{13,7}{11,0-15,0}$ & $\frac{12,1}{1,9-18,0}$ \\
\hline
\end{tabular}

Таблица 4

Распределение деревьев ели по классам Крафта и типу ветвления, \%

\begin{tabular}{|c|l|c|c|c|c|c|c|c|}
\hline \multirow{2}{*}{$\begin{array}{l}\text { № кли- } \\
\text { матипа }\end{array}$} & Происхождение (область, край, & \multicolumn{3}{|c|}{ Классы Крафтублика, лесхоз) } & \multicolumn{5}{|c|}{ Тип ветвления } \\
\cline { 3 - 10 } & респулй & 1 & $2+3$ & $4+5$ & $\Gamma$ & НГ & Щ & П \\
\hline 1 & Мурманская Мончегорский & 15 & 49 & 36 & 0 & 0 & 100 & 0 \\
\hline 20 & Архангельская Пинежский & 14 & 46 & 40 & 0 & 0 & 100 & 0 \\
\hline 23 & Архангельская Холмогорский & 19 & 46 & 35 & 0 & 0 & 100 & 0 \\
\hline 40 & Свердловская Карпинский & 16 & 45 & 39 & 0 & 0 & 100 & 0 \\
\hline 41 & Свердловская Н.-Тагильский & 22 & 31 & 47 & 0 & 0 & 100 & 0 \\
\hline 2 & Карелия Сегежский & 30 & 43 & 27 & 0 & 80 & 20 & 0 \\
\hline 19 & Архангельская Плесецкий & 15 & 46 & 39 & 44 & 0 & 56 & 0 \\
\hline 35 & Удмуртия Ижевский & 27 & 38 & 35 & 0 & 0 & 100 & 0 \\
\hline 7 & Псковская Великолукский & 31 & 44 & 25 & 0 & 0 & 100 & 0 \\
\hline 8 & Эстония Вильядинский & 20 & 54 & 26 & 0 & 0 & 100 & 0 \\
\hline 4 & Карелия Пудожский & 32 & 43 & 25 & 0 & 14 & 86 & 0 \\
\hline 24 & Вологодская Череповецкий & 22 & 39 & 39 & 0 & 0 & 100 & 0 \\
\hline 27 & Костромская Галичский & 16 & 40 & 44 & 0 & 0 & 100 & 0 \\
\hline $29 a$ & Московская Загорский & 23 & 36 & 41 & 0 & 0 & 100 & 0 \\
\hline
\end{tabular}

Примечание. Тип ветвления: Г - гребенчатый; НГ - неправильно гребенчатый, Щ - щетковидный, П - плосковетвистый.

Три разновидности ели (кроме сибирской ели) имеют весьма высокие показатели средней высоты (для деревьев, которые обладают чешуйчатым типом коры). Одновременно с этим ряд елей гибридных с признаками европейской с гладкой корой достигали наивысших показателей, до 18 метров в высоту.

В таблице 4 можно проследить обобщенное распределение ели по классам Крафта в потомствах ели разного географического происхождения.

Очевидно, что большая часть климатипов может быть отнесена ко 2-му и 3-му классу Крафта, а доля их насаждений составляет от 38 до $54 \%$ соответственно. Количество лидеров - от 14 до 39\%, угнетенных - от 25 до 47\%. Угнетенные и отмирающие деревья представлены климатипами Московской и Свердловской области (41 и 47\%). Данная тенденция объяснима разными характеристиками их родины и места испытания.

В изученных климатипах можно встретить деревья ели с щетковидным, а также с гребенчатым и нерегулярно-гребенчатым типом ветвления, что также можно про- 
следить в таблице 4. Плосковетвистый тип ветвления встречен не был. Также можно констатировать, что преобладают деревья, имеющие неправильно гребенчатый, гребенчатый и щетковидный тип ветвления, только в северо-западном климатипе.

Внутривидовые формы кроны ели сибирской и европейской представлены исключительно щетковидным типом, а гибридные формы ели имеют, помимо щитковидного типа, еще и гребенчатый, и нерегулярно гребенчатый. Долевое участие этих форм у ели гибридной с признаками сибирской превышает их представленность над щетковидным типом.

\section{Заключение}

В результате проведенного исследования можно заключить, что распространение особей по морфам находится в прямой зависимости от места, где росли исходные насаждения если. Кроме того, в данном случае усматривается зависимость от дальности переброски, вида, от особенностей популяции, а также от условий исследования. В 43-летних культурах ели наибольшее количество принадлежит елям 2-го и 3-го класса Крафта, что оценивается положительно и в полной мере соответствует оптимальному распределению насаждений.

В рамках использования продуцированных семян очень важно принимать во внимание конкретный вид ели. Предпочтение стоит отдавать тем семенам, которые были заготовлены на местности, где росли лучшие представители популяции. Рассматривая ель сибирскую, стоит отметить, что в рамках ареала ели сибирской необходимо применять местные семена данного вида и тождественные данному виду зеленые насаждения. В зоне произрастания ели европейской (в частности, юго-запад Русской равнины), а также в рамках зоны интрогрессивной гибридизации допустимо более широкое использование семян данного вида и гибридных форм определенных видов. В данном случае необходимо учитывать сходство климатических характеристик места выращивания семян и пункта их заготовки.

Также в рамках проведенного исследования было установлено, что связь 43-летних культур в части приживаемости и длины вегетационного периода характеризуется как умеренная и имеет обратный характер. За последние 18 лет отпад особей можно было наблюдать почти во всех климатипах, а суммарно данный показатель составил $10,5 \%$. Во многом это обусловлено естественным самоизреживанием климатипов. Приживаемость контрольного климатипа снизилась на 4\% и составила 74,4\%.

Наибольший процент отпада наблюдается у ели сибирской в северотаежной зоне $-6,3 \%$, и у ели гибридной с признаками европейской в южнотаежной зоне $6,2 \%$. Наименьший отпад у ели сибирской в среднетаежной и южнотаежной зонах 0,4 и $0,2 \%$ соответственно.

Гладкокорая ель занимает доминирующее положение (65-88\%). Пластинчатый тип коры характеризован высокими показателями средней высоты деревьев. При этом отдельные представители ели гибридной с признаками европейской с гладкой корой достигали наивысших показателей до 18 метров в высоту.

По типу ветвления выявлено наличие 3 форм ели: гребенчатое, неправильно гребенчатое и щетковидное. Внутривидовые формы кроны ели сибирской и европейской представлены исключительно щетковидным типом, а гибридные формы ели имеют, помимо щетковидного, еще гребенчатый и неправильно гребенчатый тип.

Результаты, полученные в рамках данного исследования, позволили уточнить видовую принадлежность климатипов, а также определить факторы влияния генетики материнских провинций на тип коры, форму кроны, приживаемость и на показатели роста. Стоит отметить, что анализ репродукции климатипов в географических культурах обладает особой важностью, так как впоследствии это поможет оптимизировать соответствующую деятельность.

Для климатипов северных и южных регионов при выращивании в географических культурах созданы равные климатические условия, что нивелирует параметры роста и развития отдельных органов растений. Одновременно с этим различия в ряде климатических показателей территорий произрастания материнских популяций и района произрастания культур нашли отражение в проявлении репродуктивных особенностей в потомстве.

\section{Список литературы / Reference}

1. Шутяев А.М., Лаврентьев Д.Д. Географические культуры дуба черешчатого в Чувашской Республике // Лесное хозяйство. 2012. № 5. С. 36-38.

Shutyaev A.M., Lavrentiev D.D. Geographical cultures of english oak in the Chuvash Republic // Lesnoye khozyaystvo. 2012. Vol. 5. P. 36-38 (in Russian).

2. Червякова Н.А., Файзулин Д.Х., Наквасина Е.Н. Динамика приживаемости климатипов ели в географических культурах Республики Коми // Экологические проблемы Арктики и северных территорий: межвузовский сборник на- 
учных трудов. Архангельск: изд-во С(А)ФУ, 2011. Вып. 14 C. 9-12.

Chervyakova N.A., Fayzulin D.H., Nakvasina E.N. The dynamics of acclimatization of spruce climatypes in the geographical cultures of the Komi Republic // Ekologicheskiye problemy Arktiki i severnykh territoriy: mezhvuzovskiy sbornik nauchnykh trudov. Arkhangel'sk: izd-vo S(A)FU, 2011. Vol. 14 P. 9-12. (in Russian).

3. Наквасина Е.Н., Прожерина Н.А., Демина Н.А. Изучение реакции потомства ели разного географического происхождения в системе «генотип-среда» на Европейском Севере России // Известия Санкт-Петербургской лесотехнической академии. 2017. № 221. С. 145-161.

Nakvasina E.N., Prozherina N.A., Demina N.A. Study of response of spruce progenies from different geographical origins in "genotype-environment» system in the European North of Russia // Izvestia Sankt-Peterburgskoj Lesotehniceskoj Akademii. 2017. № 221. P. 145-161. (in Russian).

4. Николаева М.А., Варенцова Е.Ю. Фитопатологическое состояние и сохранность ели в географических культурах Любанского лесничества Ленинградской области // Известия Санкт-Петербургской лесотехнической академии. 2019. № 228. C. 216-233.

Nikolaeva M.A., Varentsova E.Yu. Phytopathological state and preservation of spruce in the geographical cultures of the Lyuban forestry of the Leningrad region // Izvestia Sankt-Peterburgskoj lesotehniceskoj akademii. 2019. № 228. P. 216-233. (in Russian).

5. Демина Н.А., Файзулин Д.Х., Наквасина Е.Н. Структура потомства популяций ели разного географического происхождения по интенстивности роста и типам мутовчатости кроны // Лесной вестник. 2013. № 3. С. 17-21.

Demina N.A., Fayzulin D.H., Nakvasina E.N. The structure of spruce populations of different geographical origin according to the intensity of growth and the types of whorl of the crown // Lesnoy vestnik. 2013. № 3. P. 17-21 (in Russian).

6. Милютин Л.И., Новикова Т.Н. Дискуссионные проблемы лесной генетики и селекции // Лесоведение. 2019. № 6. C. 585-589.

Milyutin L.I., Novikova T.N. Open Discussions in Forest Genetics and Breeding // Lesovedeniye. 019. № 6. P. 585-589 (in Russian).

7. Проказин Е.П. Изучение имеющихся и создание новых географических культур. Пушкино: ВНИИЛМ, 1972. $52 \mathrm{c}$.

Prokazin E.P. Study of existing and creation of new geographical cultures. Pushkino: VNIILM, 1972. 52 p. (in Russian).

8. Курнаев С.Ф. Лесорастительное районирование CССР. М.: Лесная промышленность, 1973. 240 с.

Kurnaev S.F. Lesorastitelnoe rayonirovanie SSSR. M.: Lesnaya promyshlennost, 1973. 240 p. (in Russian).

9. Макаров Ю.И. Особенности роста и развития ели обыкновенной под влиянием внутривидового полиморфизма // Лесной журнал. 2016. № 3 (351). С. 87-97.

Makarov Yu.I. Fir spruce growth and development under the influence of intraspecific polymorphism // Lesnoy zhurnal.2016. № 3 (351). P. 87-97 (in Russian).

10. Наквасина Е.Н., Юдина О.А., Покатило А.В. Ростовая и репродуктивная реакции picea abies (L.) Karst. x p. obovata Ledeb. при имитации потепления климата // Вестник Северного (Арктического) федерального университета. Серия: естественные науки. 2016. № 1. С. 89-96.

Nakvasina E.N., Yudina O.A., Pokatilo A.V. Growth and reproductive response of picea abies (L.) Karst. x p. obovata Ledeb. in climate change simulation // Vestnik Severnogo (Arkticheskogo) federal'nogo universiteta. Seriya: yestestvennyye nauki. 2016. № 1. P. 89-96 (in Russian). 